\title{
Tricomponent thermoresponsive polymers based on an amine-containing monomer with tuneable hydrophobicity: Effect of composition
}

\author{
Anna P. Constantinou, Tian Lan, Dean R. Carroll and Theoni K. Georgiou* \\ Department of Materials, Imperial College London, South Kensington Campus, Royal School \\ of Mines, Exhibition Road, SW7 2AZ, London, United Kingdom
}

\begin{abstract}
In the present study, six dual-responsive $A B C$ triblock copolymers were synthesised via group transfer polymerisation (GTP) and investigated through visual inspections in terms of their thermoresponsive behaviour. The copolymers consist of i) penta(ethylene glycol) methyl ether methacrylate (PEGMA), which is hydrophilic and thermoresponsive at high temperatures, ii) $n$-butyl methacrylate (BuMA) as the hydrophobic counterpart to promote self-assembly, and iii) 2-(diethylamino)ethyl methacrylate (DEAEMA), which is pH-responsive by adjusting its hydrophilicity depending on the $\mathrm{pH}$. The effect of the degree of ionisation of DEAEMA units as well as the ionic strength effect on the self-assembly behaviour of the copolymers was tested via dynamic light scattering (DLS). The dissociation constants ( $\left.p K_{a}\right)$ of the amine units of DEAEMA were determined via potentiometric titrations. The thermoresponse has been primarily been investigated in means of cloud points (CPs) at various $\mathrm{pH}$ values in deionised water. Detailed phase diagrams were constructed for all the polymer solutions in phosphate buffered saline (PBS), with the interest being focused on the gelation area. It has been clearly proven that gelation is promoted as the content in BuMA and DEAEMA is increased. The polymer that presented the widest gelation area has been further investigated via rheology in terms of its gelation temperature, gelation time and shear-thinning properties.
\end{abstract}

Keywords: thermoresponsive polymers, 2-(diethylamino)ethyl methacrylate, penta(ethylene glycol) methyl ether methacrylate, block terpolymers, thermoresponsive gels, group transfer polymerisation (GTP)

${ }^{\star}$ Corresponding author.

E-mail address: t.georgiou@imperial.ac.iuk 


\section{Graphical Abstract:}

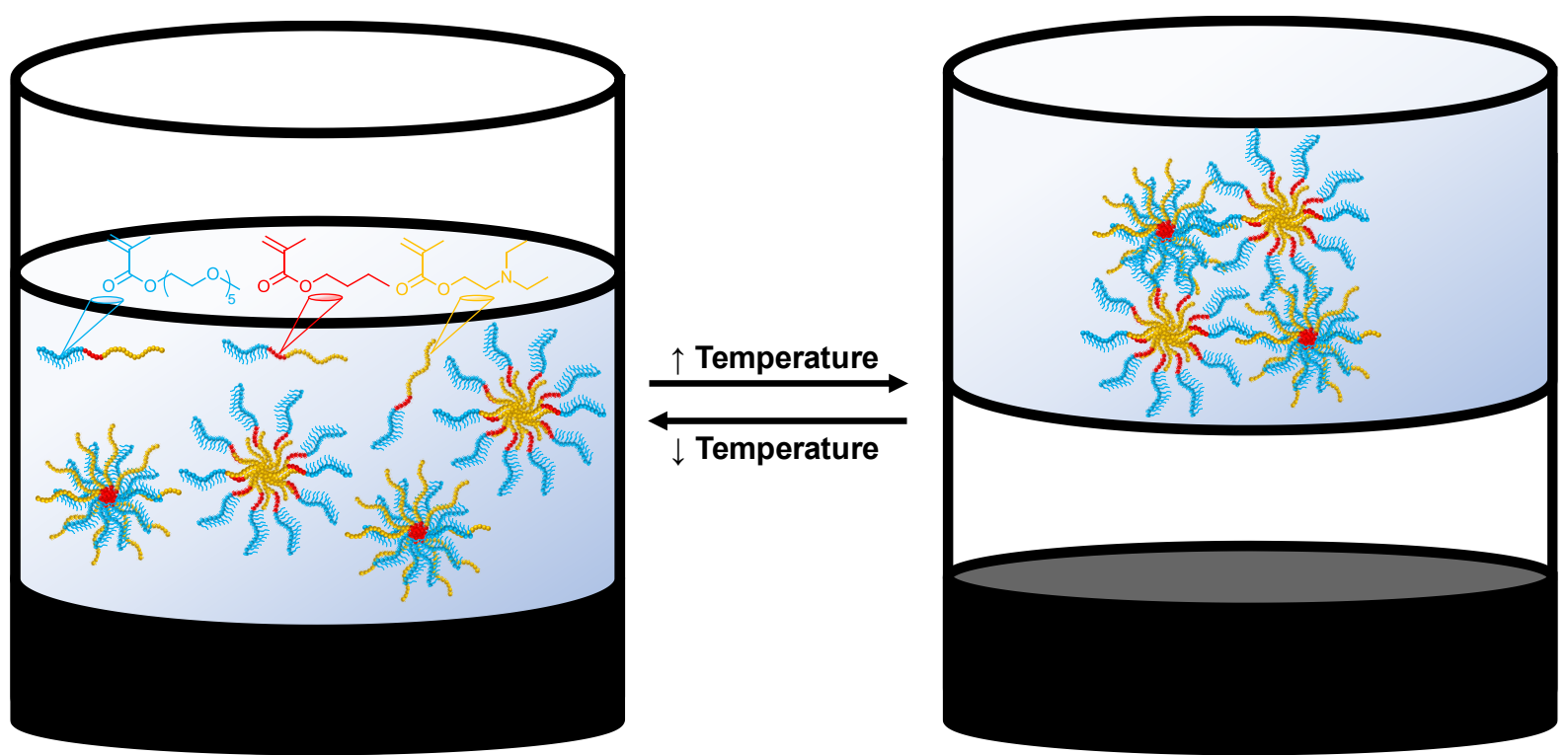




\section{Introduction}

Thermoresponsive polymers are widely studied by scientists around the world, as they do present interesting changes in their properties depending on the temperature.[1-5] Thermoresponsive polymers can either be chemically crosslinked, thus forming thermoresponsive polymeric networks (also known as chemically crosslinked gels), or can be studied without further chemical crosslinking.[3] In both cases, they are categorised in two groups, depending on how their compatibility with the solvent varies with the temperature.[1] Thermoresponsive polymers or polymeric networks which are more soluble or compatible with a solvent as the temperature increases, present upper critical solution temperature (UCST).[1, 4, 6] A well-known example of a UCST thermoresponsive polymer is gelatin.[7] On the contrary, when the solubility/compatibility with the solvent decreases as the temperature increases, they present lower critical solution temperature (LCST).[1] LCST polymers with appropriate structural characteristics can form gels via physical interactions as the temperature increases.[2]

These thermoresponsive physical gels have attracted much scientific interest because of their potential use in tissue engineering as injectable gels.[2, 8-10] In this concept, the polymer solution at room temperature is loaded with cells, and it is easily transferred to a syringe. A physical gel is formed post-injection, which is triggered by the change of the environmental temperature to body temperature. This gel matrix that contains the cells acts as a scaffold, in which the cells will form the new tissue. Ideally, the rate of tissue growth should match the rate of polymer dissolution/degradation. The use of injectable gels in the field of tissue engineering is advantageous as surgery to implant a scaffold can be avoided.[2, 8-10]

Thermoresponsive gels have also been studied as drug delivery systems.[11-15] It has been proven in several studies that incorporating the drug in the gel matrix is beneficial, as it controls the drug release rate for prolonged periods. Also, topical drug delivery, as opposed to systemic drug delivery, is advantageous as it minimises the side effects.[11-15]

More recently, thermoresponsive gels have been investigated as 3-D printable materials.[2, 16-26] The use of thermoresponsive gels in 3-D printing facilitates the easy loading into the syringe of the printer, which is then heated to the desired temperature to promote gelation. In 3-D printing, thermoresponsive gels are used as sacrificial materials, either to facilitate the printing of another material, e.g. graphene,[19] or to print more complicated structures. In the first case, the thermoresponsive gel is mixed with the material in interest, while in the second case, the thermoresponsive gel is printed within the permanent structure. In both cases, the temperature of the printed construct is lowered after printing, and thus the physical gel returns to the solution phase thus a structure consisting of the permanent material remains.[2, 16-26] In addition to its thermoresponsive properties, and thus its reversible gelation properties, the ink should possess shear-thinning properties, i.e. the viscosity should decrease with increased shear rate, and thus the easier the printing process is.[27-29] Therefore, as thermoresponsive gels are widely studied not 
only by polymer chemists but also by material scientists and (bio-)engineers, there is an increase of interest in fabrication of new thermoresponsive polymers.

Several thermoresponsive polymers have been reported in the literature. Among the most popular thermoresponsive units, which have been investigated either as homopolymers or co-polymers are $\mathrm{N}$-isopropylacrylamide (NIPAAm),[30-33] ethylene glycol (EG),[34, 35] 2-(dimethylamino) ethyl methacrylate (DMAEMA),[36-42] various EG-based (meth-)acrylates, [33, 43-49] and poly(oxazoline)s[50-55]. The most welldocumented thermoresponsive polymer is Poloxamer 407 (also known with its trademark name Pluronic $\circledast$ F127), which is based on EG and propylene glycol (PG).[22, 56-63]

The synthesis of new thermoresponsive polymers by polymer chemists can be facilitated by various polymerisation techniques, either anionic or radical polymerisations. In either case, well-defined polymers (narrow dispersity) should be synthesised, as it is well-established that polymers with different molar mass (MM), and composition present different thermoresponse.[2] Therefore, "living" or controlled polymerisation methods should be implemented. In the current study, group transfer polymerisation (GTP) has been chosen as the fabrication method, as it fulfils the aforementioned criterion, and also it is time-effective, cost-effective and industrially applicable.[64-66] More specifically, GTP has been invented in DuPont in 1980's, and it is completed within 15 mins (per block) and at room temperature. The monomer conversion is $100 \%$, thus no intermediate purification steps are required.[64-66]

Our group has previously published several research papers on thermoresponsive polymers.[37-42, 67] More specifically, our studies have been focused on amphiphilic block copolymers (mostly diblock and triblock copolymers, or tetrablock copolymers), and clear trends have been established in each study. These studies have shown that each structural parameter, i.e. architecture,[37, 39, 41, 42] composition[38-40, 42, 67] and $\mathrm{MM},[38]$ is decisive for the final thermoresponsive properties. In these studies, various monomers have been used, such as poly(ethylene glycol) (PEG)-based[67] and alkyl-based methacrylate monomers of various lengths, [37] as the hydrophilic and hydrophobic units, respectively. In all the studies, a hydrophilic and $\mathrm{pH}$ - and thermoresponsive amine-containing monomer was incorporated into the structure, namely DMAEMA.[37-42, 67] DMAEMA has been thoroughly investigated in the past for its thermoresponsive and $\mathrm{pH}$-responsive properties, and its cloud point (CP) and dissociation constant $\left(\mathrm{p} K_{\mathrm{a}}\right)$ are well documented in the literature.[36, 68-70] More specifically, the $\mathrm{p} K_{\mathrm{a}}$ of the conjugate acid form of the DMAEMA amine is around 7.0, while its $\mathrm{CP}$ decreases from $46^{\circ} \mathrm{C}$ to $32^{\circ} \mathrm{C}$, as the $\mathrm{MM}$ increases from $1450 \mathrm{gmol}^{-1}$ to $53000 \mathrm{gmol}^{-1}$.[36] In most of the studies, penta(ethylene glycol) methyl ether methacrylate (PEGMA) was used as the hydrophilic unit, which is also thermoresponsive but at higher temperatures than DMAEMA; it has been reported that its $\mathrm{CP}$ is $64^{\circ} \mathrm{C}, \mathrm{MM}$ dependent.[71] Concerning the length of the alkyl group, it has been concluded that polymers containing $n$-butyl methacrylate (BuMA) form stronger gels.[37] For the systems that have been investigated by our group, it has been observed that the triblock copolymers with i) the hydrophobic block in the centre of the polymer chain,[39, 41] ii) target $\mathrm{MM}$ around 7600 to $8300 \mathrm{gmol}^{-1},[38]$ and iii) hydrophobic BuMA content between $30 \mathrm{w} / \mathrm{w} \%$ and $40 \mathrm{w} / \mathrm{w} \%,[39,67]$ show clear sol- 
gel transition, i.e. they are soluble at low temperatures and form a gel at higher temperatures, without presenting any solubility issues.

In our latest study, block copolymers based on PEGMA and the pH-responsive 2(diethylamino)ethyl methacrylate (DEAEMA) have been investigated for their use as precursors for fabrication of gold nanoparticles (AuNPs).[72] DEAEMA is known to be $\mathrm{pH}$-responsive, as its hydrophilicity changes depending on the $\mathrm{pH}$.[36, 72-76] More specifically, at alkaline environment $\left(\mathrm{pH}\right.$ higher than its $\left.\mathrm{p} K_{\mathrm{a}} \sim 7.3\right)$, DEAEMA homopolymer is hydrophobic, and thus water-insoluble.[36, 74, 76] On the other hand, at acidic conditions ( $\mathrm{pH}$ lower than its $\mathrm{p} K_{\mathrm{a}}$ ), the amino groups are protonated and hydrophilic and thus the DEAEMA homopolymer is soluble in water.[36, 74, 76] When DEAEMA is compared to DMAEMA, DEAEMA is a stronger base, indicated by its higher $\mathrm{p} K \mathrm{a}$ value (weaker conjugate acid).[36]

In the present study, we wanted to investigate the effect of replacing the DMAEMA units with DEAEMA units will affect the solution properties of these methacrylate based triblock copolymers. Thus, to study how the incorporation of the $\mathrm{pH}$ responsive DEAEMA units, which are hydrophobic at alkaline $\mathrm{pH}$ and hydrophilic at acidic $\mathrm{pH}$, affect the thermoresponsive properties, as it is well established that the hydrophobicity affects the thermoresponsive/gelation properties. Therefore, we investigate in more detail the thermoresponsive behaviour of dual-responsive $A B C$ triblock copolymers based on PEGMA ( $A$ unit), BuMA (B unit), and DEAEMA ( $C$ unit). Six triblock copolymers of various compositions were synthesised via GTP. The hydrophobic BuMA content was kept constant either at $10 \mathrm{w} / \mathrm{w} \%$ (Family A), or at $20 \mathrm{w} / \mathrm{w} \%$ (Family $B)$. Since DEAEMA units are more hydrophobic than DMAEMA units, the hydrophobic content was kept at lower values than the optimum hydrophobic content determined for DMAEMA-containing polymers to ensure that the polymers are water-soluble. In the first family, three ABC compositions were targeted: i) 50-10-40 w/w\%, ii) $45-10-45$ $\mathrm{w} / \mathrm{w} \%$, and iii) 40-10-50 w/w\%, whereas in the second family, the compositions were: i) 55-20-25 w/w\%, 50-20-30 w/w\%, and 45-20-35 w/w\%. In the present study, all the copolymers were extensively investigated through visual tests in terms of their thermoresponsive behaviour. 


\section{Materials and Methods}

The monomers, PEGMA (MM = $\left.300 \mathrm{~g} \mathrm{~mol}^{-1}\right)$, BuMA (99\%), and DEAEMA (99\%), the initiator, methyl trimethylsilyl dimethylketene acetal (MTS, 95\%), the purifying agents, aluminium oxide activated basic $\left(\mathrm{Al}_{2} \mathrm{O}_{3} \cdot \mathrm{KOH}\right)$, and calcium hydride $\left(\mathrm{CaH}_{2}, \geq 90 \%\right)$, the free-radical inhibitor, 2,2-diphenyl-1-picrylhydrazyl hydrate (DPPH), the polymerisation solvent, tetrahydrofuran (THF, HPLC grade, $\geq 99.9 \%$ ), and sodium and potassium metals were purchased from Sigma Aldrich. The precipitation solvent, $n$ hexane, was purchased from VWR Chemicals, while phosphate buffered saline (PBS, 10x solution) was purchased from Fisher Scientific. Tetrabutylammonium hydroxide ( $40 \%$ in water), which was used for the catalyst synthesis, as it is discussed in the following paragraphs, was acquired from Acros Organics.

The monomers were purified by i) passing twice through basic aluminium oxide, and ii) stirring under $\mathrm{CaH}_{2}$ for at least $3 \mathrm{~h}$. These steps were followed to ensure an acidfree environment, e.g. removal of the polymerisation inhibitor and methacrylic acid, and ii) a humidity-free environment. DPPH has been added in the low MM monomers, BuMA and DEAEMA, to prevent undesired polymerisation and these monomers were vacuum-distilled prior to use, whereas the high MM monomer PEGMA was diluted in THF $(50 \mathrm{v} / \mathrm{v} \%)$ prior to any purification step and was syringed directly in the polymerisation flask using $0.45 \mu \mathrm{m}$ PTFE filters. The initiator was vacuum-distilled prior to use, while the polymerisation solvent was dried by refluxing for 3 days in sodiumpotassium alloy. All the chemicals were kept under inert argon conditions. The catalyst was synthesised by tetrabutylammonium hydroxide and benzoic acid, as reported previously,[77] it was recrystallised in diethyl ether and it was vacuum-dried prior to use. All the glassware used during the polymerisation and distillation were dried overnight at $140^{\circ} \mathrm{C}$ prior to use. The chemical structures of the monomers used in this study, the initiator and the catalyst are presented in Figure 1. 
<smiles>C=C(C)C(=O)OCCOC(C)(C)C</smiles>

Penta(ethylene glycol) methyl ether methacrylate

(PEGMA)

Non-ionic hydrophilic and thermoresponsive<smiles>COC(O[Si](C)(C)C)=C(C)C</smiles>

Methyl trimethylsilyl

dimethylketene acetal

(MTS)

Initiator<smiles>C=C(C)C(=O)OCCCC</smiles>

n-Butyl methacrylate

(BuMA)

Non-ionic hydrophobic

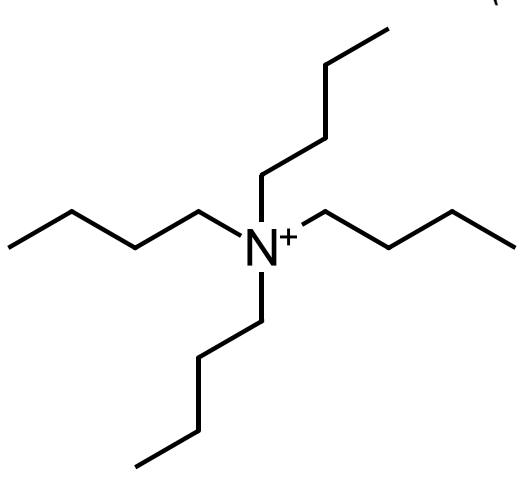<smiles>C=C(C)C(=O)OCCN(CC)CC</smiles>

2-(Diethylamino)ethyl methacrylate

(DEAEMA)

Ionic and $\mathrm{pH}$-responsive (tunable hydrophobicity)<smiles>O=C([O-])c1ccccc1C(=O)O</smiles>

Tetrabutylammonium

bibenzoate (TBABB)

Catalyst

Figure 1: Chemical structures, names and abbreviations of the monomers, the initiator and the catalyst used in this study.

\section{Triblock Copolymer Synthesis and Recovery}

All the triblock copolymers were synthesised via sequential GTP, in a similar procedure as reported in the literature.[64] The synthesis of Polymer 1, PEGMA $12.5-b$ BuMA5-b-DEAEMA ${ }_{16}$, is reported as an example. Specifically, $10 \mathrm{mg}$ of TBABB was added in a $250 \mathrm{~mL}$ round-bottom flask, which was sealed immediately with rubber septum and purged with argon to ensure inert atmosphere. Freshly distilled THF (37.9 $\mathrm{mL}$ ) was injected in the polymerisation flask, followed by the injection of the initiator $(0.4 \mathrm{~mL}, 0.3 \mathrm{~g}, 2.0 \mathrm{mmol})$. Then, the monomer additions followed as described: i) PEGMA solution (14.1 mL, $7.34 \mathrm{~g}, 25.0 \mathrm{mmol}$ ), ii) BuMA (1.7 mL, $1.5 \mathrm{~g}, 10 \mathrm{mmol}$ ), and iii) DEAEMA (6.4 mL, $5.9 \mathrm{~g}, 32 \mathrm{mmol})$. It should be mentioned that each monomer injection was performed every 15 mins, which is the time interval that ensures that the polymerisation is complete. The temperature variation was monitored after each addition. Two $0.1 \mathrm{~mL}$ aliquots were withdrawn after the completion of each block polymerisation for GPC and ${ }^{1} \mathrm{H}$ NMR analysis. The other triblock copolymers were synthesised in a similar manner. In all the cases, the polymerisation yield was quantitative (i.e. $100 \%$ yield), which is a characteristic of GTP. All the polymers were recovered by precipitation in cold $n$-hexane and the traces of $n$-hexane and THF were removed by drying in a vacuum oven at room temperature. 


\section{Characterisation in Organic Solvents}

\section{Gel Permeation Chromatography (GPC)}

GPC was utilised to determine the MM and MMDs of the polymers and their linear precursors. The SECurity GPC system was purchased from Agilent, and it is equipped with a Polymer Standard Service (PSS) SDV analytical linear M column (SDA083005LIM), an Agilent 1260 refractive index (RI) detector, and a "1260 Iso" isocratic pump. The GPC solvent was THF/Et $3 \mathrm{~N}$ solution (95/5 v/v\%). Prior to the measurements, the GPC system was calibrated using six poly(methyl methacrylate) standard samples of well-defined MMs: 2000, 4000, 8000, 20000, 50000, and 100000 $\mathrm{g} \mathrm{mol}^{-1}$.

\section{Proton Nuclear Magnetic Resonance ('H NMR) Spectroscopy}

An Avance Bruker $400 \mathrm{MHz}$ NMR system was used to determine the compositions of the copolymers and their precursors (homopolymers and diblock copolymers). $\mathrm{CDCl}_{3}$ was used as the NMR solvent.

\section{Characterisation in Aqueous Solvents}

\section{Potentiometric titrations}

Hydrogen ion titrations were performed on $1 \mathrm{w} / \mathrm{w} \%$ polymer solutions in DI water to determine the $\mathrm{p} K_{\mathrm{a}}$ values of DEAEMA units. For this experiment, a portable HI98103 $\mathrm{pH}$ checker was used, which was calibrated at $\mathrm{pH} 4$ and $\mathrm{pH} 7$ prior to each experiment. The $\mathrm{p} K_{\mathrm{a}}$ is determined as the $\mathrm{pH}$ at which $50 \mathrm{~mol} \%$ of the DEAEMA are protonated.

\section{Dynamic Light Scattering (DLS)}

Dynamic Light Scattering (DLS) was performed in all polymer solutions at a concentration of $1 \mathrm{w} / \mathrm{w} \%$ in either DI water or PBS. A Zetasizer Nano ZSP instrument was utilised for this experiment. The DLS analysis in DI water was performed at three different $\mathrm{pH}$ values: i) initial $\mathrm{pH}$, which varied between 7.1-7.6, ii) acidic $\mathrm{pH}(\mathrm{pH} 5)$, and alkaline $\mathrm{pH}(\mathrm{pH}$ 8). Prior to the measurement, the samples were filtered using nylon $0.45 \mu \mathrm{m}$ for removing any dust and big aggregates. The experiments were conducted at room temperature and the results were obtained by collected the light at a backscatter angle of $173^{\circ}$. The results are reported as the average of the size corresponding to the maximum by intensity. In case more than one peak were detected, the results reported are the ones corresponding to the peak of micelles.

The experimental diameters were compared to the theoretical ones. Two different models were used for calculating the diameters of the triblock copolymers. According to the first model, the cores of the micelles were formed only by the hydrophobic BuMA blocks, while the corona of the micelle formed by both PEGMA blocks and DEAEMA blocks. This model assumes that DEAEMA is fully hydrophilic, which is the case at low $\mathrm{pH}$ values (below the $\mathrm{p} K_{\mathrm{a}}$ value). The equation used to calculate the hydrodynamic diameter is $d=\left[D P_{\text {BumA }}+2^{*} D P_{\text {longest hydrophilic }}{ }^{*} 0.254 \mathrm{~nm}\right.$; where DP stands for degree 
of polymerisation. The second model assumes that both BuMA and DEAEMA blocks are hydrophobic, thus they contribute to the formation of the cores of the micelles, while the corona of the micelle was formed by the hydrophilic PEGMA blocks only; DEAEMA is considered hydrophobic at high $\mathrm{pH}$ values, at which the amino groups are not protonated (above the $\mathrm{p} K_{\mathrm{a}}$ value). The equation used to calculate the hydrodynamic diameter is $d=\left[\left(D_{\text {BuMA }}+\right.\right.$ DP DEAEMA $)+2^{*}$ DP PEGMA $^{*} 0.254 \mathrm{~nm}$. The DPs used for these calculations are the experimental ones calculated by using the GPC results after precipitation and the ${ }^{1} \mathrm{H}$ NMR results before precipitation.

\section{Visual Tests}

The polymer solutions were visually tested from $20^{\circ} \mathrm{C}$ to $80^{\circ} \mathrm{C}$ at various concentrations and aqueous solvents. The experiment was conducted using an IKA RCT stirrer hotplate and an IKA ETS-D5 temperature controller. The vials were immersed in a continuously stirred water-bath and observations were obtained every degree. $1 \mathrm{w} / \mathrm{w} \%$ polymer solutions in deionised (DI) water, both at initial $\mathrm{pH}(\mathrm{pH}$ varying between $7.1-7.5$ ) and at $\mathrm{pH}$ 8, were investigated for a $\mathrm{CP}(\mathrm{CP})$ (temperature at which the transparent solutions turn to cloudy). The polymer solutions in phosphate buffered saline (PBS) were investigated at various concentration for gelation. More specifically, $1,2,5,10,15,20,25$ and $30 \mathrm{w} / \mathrm{w} \%$ of the polymer solutions were tested and detailed phase diagrams were constructed. Nine transitions are stated in the phase diagrams: i) solution phase (clear, slightly cloudy, and cloudy), ii) viscous solution phase (transparent and cloudy), iii) gel phase (transparent and cloudy), and iv) two-phases system (gel syneresis and precipitation). Detailed pictures that define each state are reported in our previous publication in Constantinou et al. 2017.[41]

\section{Rheology}

The best-performing polymer of this study was tested rheologically at $30 \mathrm{w} / \mathrm{w} \%$ in PBS, as at which concentration presented the widest gelation area. The analysis was performed using a TA discovery HR-1 hybrid rheometer, which was equipped with a $40 \mathrm{~mm}$ parallel Peltier steel plate (996921). Firstly, a temperature ramp measurement was performed from $40^{\circ} \mathrm{C}$ to $60^{\circ} \mathrm{C}$, as this was the area of interest according to the visual tests. Secondly, after determining the gelation temperature rheologically, the gelation time was tested at $49^{\circ} \mathrm{C}$. During both measurements, the strain was kept constant at $1 \%$, while the angular frequency applied was at 1 rads $^{-1}$. The gel was investigated further for its shear-thinning properties from $0.01 \mathrm{~s}^{-1}$ to $100 \mathrm{~s}^{-1}$. As all the measurements were performed at temperatures higher than room temperature, a solvent trap was used to prevent solvent evaporation. 


\section{Results and Discussion}

This study investigates the synthesis of six novel $A B C$ triblock copolymers via GTP. The $A, B$ and $C$ blocks consisted of PEGMA, BuMA and DEAEMA units, respectively. The MM of the copolymers was kept constant at $7600 \mathrm{~g} \mathrm{~mol}^{-1}$. This value is within the optimum MM range proven determined by our previous study on DMAEMA-based polymer for producing copolymers with clear-sol gel transition.[38] The composition of the triblock copolymers was varied to investigate its effect on the thermoresponsive properties of the copolymers. More specifically, two families, each consisting of three copolymers, with different BuMA content were synthesised. The six different PEGMABuMA-DEAEMA compositions targeted are: i) first family with $10 \mathrm{w} / \mathrm{w} \%$ BuMA content (50-10-40, 45-10-45, and 40-10-50 w/w\%), and ii) second family with $20 \mathrm{w} / \mathrm{w} \%$ BuMA content (55-20-25, 50-20-30, and 45-20-35 w/w\%). The BuMA content in this study was targeted at lower values than the optimum range proven in the previous studies, in which the polymers consisted of DMAEMA instead of DEAEMA, [37-42, 67] to ensure solubility (DEAEMA is more hydrophobic than DMAEMA). The polymer structures studied in the current study are schematically illustrated in Figure 2, in which the PEGMA, BuMA, and DEAEMA units are represented by light blue, red, and yellow spheres, respectively.

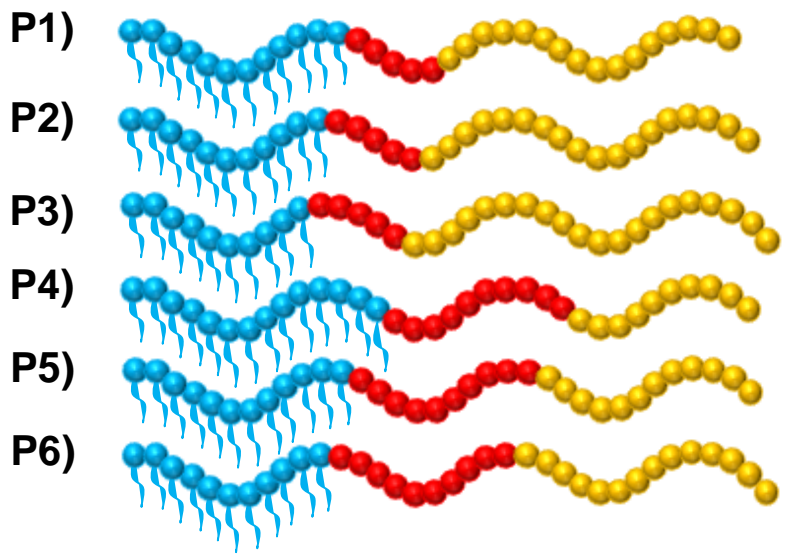

$$
\begin{aligned}
& \text { PEGMA }_{12.5}-b-\mathrm{BuMA}_{5}-b-\mathrm{DEAEMA}_{16} \\
& \text { PEGMA }_{11}-b-\mathrm{BuMA}_{5}-b-\mathrm{DEAEMA}_{18} \\
& \text { PEGMA }_{10}-b-\mathrm{BuMA}_{5}-b-\mathrm{DEAEMA}_{20} \\
& \text { PEGMA }_{14}-b-\mathrm{BuMA}_{10.5}-b-\mathrm{DEAEMA}_{10} \\
& \text { PEGMA }_{12}-b-\mathrm{BuMA}_{10.5}-b-\mathrm{DEAEMA}_{12} \\
& \text { PEGMA }_{11}-b-\mathrm{BuMA}_{10.5}-b-\mathrm{DEAEMA}_{14}
\end{aligned}
$$

Figure 2: Schematic of structures of polymers investigated in this study. PEGMA, BuMA, and DEAEMA units are represented by light blue, red, and yellow spheres, respectively.

\section{Structural Properties}

The synthesis was monitored via GPC and ${ }^{1} \mathrm{H}$ NMR spectroscopy. The molar mass characteristics (resulted from GPC) of the polymers and their linear precursors, and the compositions (resulted from ${ }^{1} \mathrm{H}$ NMR) are summarised in Table 1. Table 1 also shows the theoretical MM and composition values. 
Table 1: Theoretical polymer structures, theoretical molar masses, experimental numberaverage molar masses and dispersity indices, and theoretical and experimental compositions of the terpolymers and their linear precursors.

\begin{tabular}{|c|c|c|c|c|c|c|}
\hline \multirow{2}{*}{ No } & \multirow{2}{*}{ Theoretical polymer structure ${ }^{a}$} & \multirow{2}{*}{$\begin{array}{c}\mathrm{MM}_{\mathrm{b}}^{\text {theor. }} \\
\left(\mathrm{g} \mathrm{mol}^{-1}\right)\end{array}$} & \multirow{2}{*}{$\begin{array}{c}M_{\mathrm{n}}^{\mathrm{c}} \\
\left(\mathrm{g} \mathrm{mol}^{-}\right. \\
1)\end{array}$} & \multirow{2}{*}{$\boldsymbol{\theta}^{\mathrm{c}}$} & \multicolumn{2}{|c|}{$\begin{array}{l}\text { PEGMA-BuMA- } \\
\text { DEAEMA w/w\% }\end{array}$} \\
\hline & & & & & Theoretical & $\begin{array}{l}\text { By }{ }^{1} \mathrm{H} \\
\text { NMR }\end{array}$ \\
\hline \multirow{3}{*}{1} & PEGMA $_{12.5}$ & 3850 & 5400 & 1.14 & $100-00-00$ & $100-00-00$ \\
\hline & PEGMA $_{12.5}-b-\mathrm{BuMA}_{5}$ & 4600 & 6100 & 1.16 & $83-17-00$ & $81-19-00$ \\
\hline & PEGMA $_{12.5}-b-$ BuMA $_{5}-b-$ DEAEMA $_{16}$ & 7600 & 9800 & 1.21 & $50-10-40$ & 48-13-39 \\
\hline \multirow{3}{*}{2} & PEGMA $_{11}$ & 3475 & 5400 & 1.16 & $100-00-00$ & $100-00-00$ \\
\hline & PEGMA $_{11}-b-$ BuMA $_{5}$ & 4225 & 6600 & 1.15 & $82-18-00$ & $79-21-00$ \\
\hline & PEGMA $_{11}-b-\mathrm{BuMA}_{5}-b-\mathrm{DEAEMA} \mathrm{A}_{18}$ & 7600 & 11800 & 1.21 & $45-10-45$ & $44-13-43$ \\
\hline \multirow{3}{*}{3} & PEGMA $_{10}$ & 3100 & 4500 & 1.15 & $100-00-00$ & $100-00-00$ \\
\hline & PEGMA $_{10}-b-$ BuMA $_{5}$ & 3850 & 5200 & 1.16 & $80-20-00$ & $77-23-00$ \\
\hline & PEGMA $_{10}-b-\mathrm{BuMA}_{5}-b-\mathrm{DEAEMA} \mathrm{A}_{20}$ & 7600 & 10900 & 1.17 & $40-10-50$ & $37-11-52$ \\
\hline \multirow{3}{*}{4} & PEGMA $_{14}$ & 4225 & 6400 & 1.15 & $100-00-00$ & $100-00-00$ \\
\hline & PEGMA $_{14}-b-B_{10 M A_{10.5}}$ & 5725 & 7900 & 1.15 & $73-27-00$ & $72-28-00$ \\
\hline & PEGMA $_{14}-b-\mathrm{BuMA}_{10.5}-b$-DEAEMA 10 & 7600 & 9900 & 1.19 & $55-20-25$ & $54-21-25$ \\
\hline \multirow{3}{*}{5} & PEGMA $_{12}$ & 3850 & 5100 & 1.16 & $100-00-00$ & $100-00-00$ \\
\hline & PEGMA $_{12}-b-$ BuMA $_{10.5}$ & 5350 & 7200 & 1.14 & $71-29-00$ & $69-31-00$ \\
\hline & PEGMA $_{12}-b-$ BuMA $_{10.5}-b-$ DEAEMA $_{12}$ & 7600 & 9900 & 1.16 & $50-20-30$ & $49-22-29$ \\
\hline \multirow{3}{*}{6} & PEGMA $_{11}$ & 3475 & 4200 & 1.15 & $100-00-00$ & $100-00-00$ \\
\hline & PEGMA $_{11}-b-$ BuMA $_{10.5}$ & 4975 & 5800 & 1.14 & $69-31-00$ & $68-32-00$ \\
\hline & PEGMA $_{11}-b$-BuMA ${ }_{10.5}-b$-DEAEMA 14 & 7600 & 8900 & 1.13 & $45-20-35$ & $47-21-32$ \\
\hline
\end{tabular}

a PEGMA, BuMA and DEAEMA stand for penta(ethylene glycol) methyl ether methacrylate, $n$ butyl methacrylate and 2-(diethylamino)ethyl methacrylate, respectively.

b The theoretical molar mass (MM) is calculated by summing the MM of PEGMA, BuMA, and DEAEMA parts, and $100 \mathrm{~g} \mathrm{~mol}^{-1}$ is added to the final result, as a part of the initiator stays on the polymer chain. The MM of each part is calculated by multiplying the degree of polymerisation (DP) by the MM of the corresponding repeated unit.

c The $M_{\mathrm{n}}$ and $\boxminus$ values resulted after GPC analysis, which was based on linear calibration curve with 6 poly(methyl methacrylate) (PMMA) standard samples of MM equal to 2, 4, 8, 20, 50 , and $100 \mathrm{kDa}$.

\section{Molar Mass characteristics}

As can be seen in Table 2, the experimental MM values (number-average MM, $M_{n}$ ) vary between 8900 and $11800 \mathrm{~g} \mathrm{~mol}^{-1}$. These values are higher than the theoretical ones $\left(7600 \mathrm{~g} \mathrm{~mol}^{-1}\right)$, but still within the desirable range which produces polymers with clear sol-gel transition. The discrepancy of the theoretical and experimental MM values is attributed to the deactivation of the initiator (MTS) molecules because of the presence of humidity and impurities. This effect has been previously observed in GTPstudies on PEG macromonomers, i.e. monomers with average molar mass, that cannot be distilled because of their high MM.[42, 78]

The $\Xi$ values of the final terpolymers are between 1.13 and 1.21. These values prove that the GTP was successful and well-defined polymers consisting of PEG macromonomers were produced, and they are in agreement with previous results published on GTP synthesis.[42, 78] It is noteworthy that the triblock copolymers with 
higher PEGMA content present higher $\oslash$ values, which shows that the dispersity results from the use of macromonomer, i.e. a monomer with average molar mass, and not well-defined monomers.

The GPC traces of PEGMA $12.5-b$-BuMA 5 - $b$-DEAEMA 16 and its precursors (i.e. $P_{E G M A} 12.5$ and PEGMA $12.5-b$-BuMA 5 ) are presented in Figure 3 . More specifically, the GPC traces of the triblock terpolymer before and after precipitation are shown in yellow solid and dashed lines, whereas light blue and red show the MM profiles of the homopolymer and diblock copolymer, respectively. As can be observed, the peak moves to higher MM values as the polymerisation progresses. Also, the GPC profiles are of narrow distribution, which proves the successful "living" GTP. The traces of shoulder present on the GPC traces of the final terpolymer are associated with the PEGMA homopolymer, which slightly deactivated the initiator, as observed in previous studies.[37, 41, 42, 67, 72] The GPC traces of the syntheses of the other triblock terpolymers are presented in Figure $\mathrm{S} 1$ in the Supporting Information and they show similar profiles.

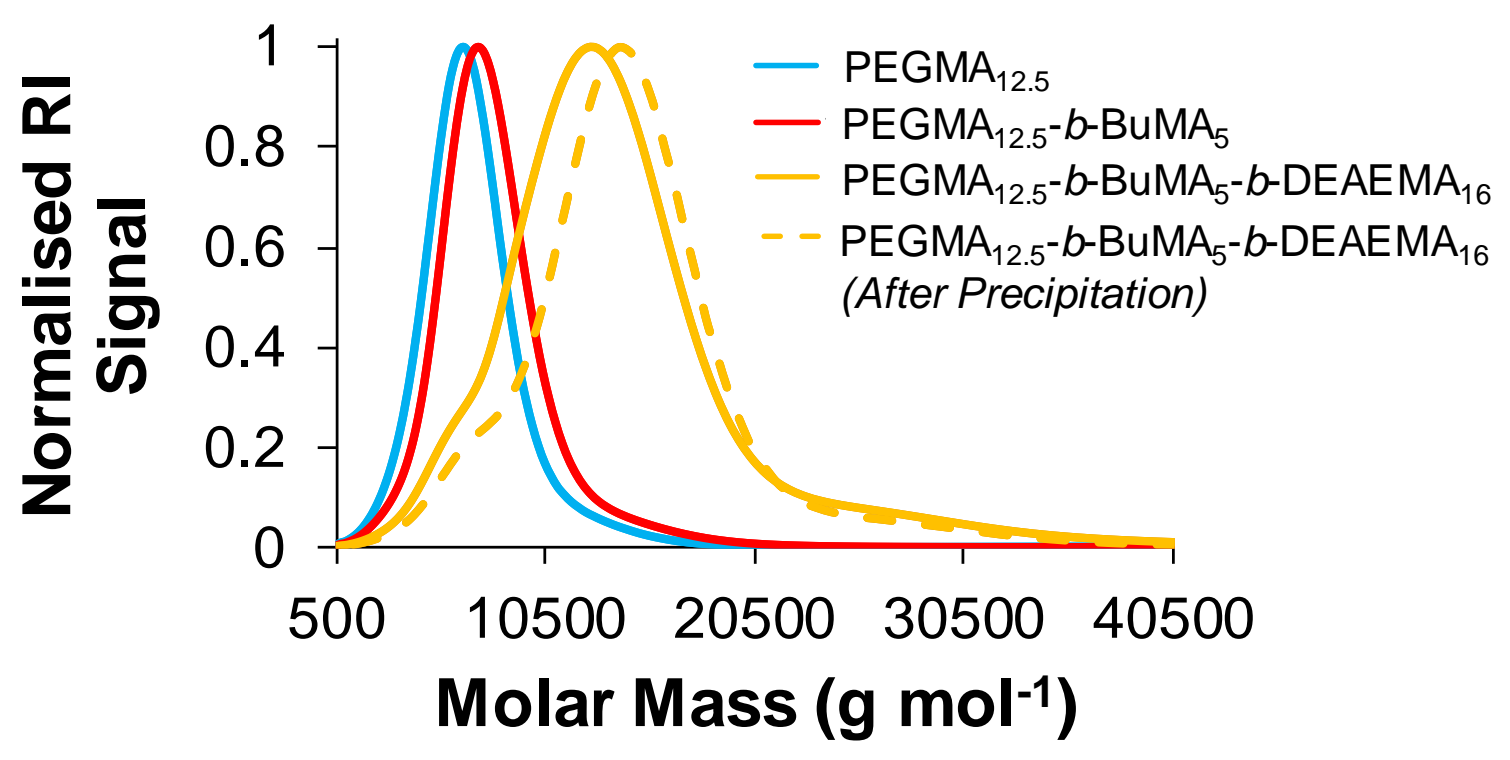

Figure 3: GPC traces showing synthetic steps of Polymer 1, PEGMA $A_{12.5}-b-B_{1} A_{5}-b$ $D_{E A E M A_{16}}$. Its $M M$ profile before and after precipitation are presented in yellow solid and dashed lines. The GPC traces of its precursors are shown in blue $\left(P E G M A_{12.5}\right)$ and red

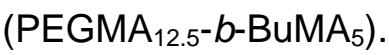

\section{Polymer Composition}

The compositions of the final terpolymers, homopolymer precursors and diblock copolymer precursors were analysed via ${ }^{1} \mathrm{H}$ NMR and an example of the NMR analysis of the synthesis of Polymer 1 is presented in Figure S2 in the Supporting Information. The calculations of the experimental values are based on three distinct peaks, each corresponding to a different repeated unit. In particular, the peak of the three methoxy protons in PEGMA units $\left(\mathrm{CH}_{3} \mathrm{O}-\right)$ appears at $3.35 \mathrm{ppm}$, while the distinct peak of the two methyl protons on the second carbon from the ester bond $\left(-\mathrm{OCH}_{2} \mathrm{CH}_{2} \mathrm{CH}_{2} \mathrm{CH}_{3}\right)$ appear in 1.5-1.6 ppm. Concerning the DEAEMA unit, two distinct peaks appear in the 
area between 2-4 and 2-7ppm which correspond to the protons closer to the nitrogen atom. For the calculations, the second peak (higher ppm) was used, and it belongs to the four protons of the final ethyl groups [- $\left.\mathrm{OCH}_{2} \mathrm{CH}_{2} \mathrm{~N}\left(\mathrm{CH}_{2} \mathrm{CH}_{3}\right)_{2}\right]$. The experimental composition, listed in Table 1, are in good agreement with the theoretical/targeted values, within the experimental error of the NMR technique.

\section{Properties in Aqueous Solutions}

The self-assembly behaviour in various aqueous solvents and $\mathrm{pH}$ values, the strength of the amine groups, as well as the thermoresponsive behaviour of the terpolymers in aqueous solutions have been tested and are discussed in the following sections. The results are summarised in Table 2.

Table 2: Theoretical polymer structures, theoretical diameters based on two different models and experimental hydrodynamic diameters in $\mathrm{DI}$ water at various $\mathrm{pH}$ and in PBS, dissociation constants, and cloud points in DI water.

\begin{tabular}{|c|c|c|c|c|c|c|c|c|c|}
\hline \multirow{3}{*}{ No } & \multirow{3}{*}{ Theoretical polymer structure $^{a}$} & \multicolumn{6}{|c|}{ Diameter of the micelles (nm) } & \multirow{3}{*}{$\begin{array}{r}\mathrm{p} K_{\mathrm{a}} \\
\pm 0.1\end{array}$} & \multirow{3}{*}{$\begin{array}{c}C P \\
\pm 2\left({ }^{\circ} \mathrm{C}\right)\end{array}$} \\
\hline & & \multicolumn{2}{|c|}{ Theoretical $^{b}$} & \multicolumn{4}{|c|}{ Experimental by DLS ${ }^{\mathrm{e}}$} & & \\
\hline & & $1^{c}$ & $2^{d}$ & $\mathrm{pH}^{\text {initial } \mathrm{f}}$ & pH 8 & pH 5 & PBS & & \\
\hline 1 & PEGMA $_{12.5-b-B_{1 M A}-b-D E A E M A_{16}}$ & 14.3 & 17.4 & 21.0 & 28.2 & 18.2 & 24.4 & 6.8 & 61 \\
\hline 2 & PEGMA $_{11}-b-$ BuMA $_{5}-b$-DEAEMA ${ }_{18}$ & 16.9 & 18.8 & 24.4 & 32.7 & 21.0 & 28.2 & 7.1 & 6 \\
\hline 3 & PEGMA $_{10}-b-$ BuMA $_{5}-b-$ DEAEMA $_{20}$ & 16.4 & 15.5 & 18.2 & 28.2 & 18.2 & 24.4 & 7.1 & 68 \\
\hline 4 & PEGMA $_{14}-b-$ BuMA $_{10.5}-b$-DEAEMA 10 & 15.0 & 18.9 & 43.8 & 32.7 & 15.7 & 32.7 & 6.2 & 62 \\
\hline 5 & PEGMA $_{12}-b-$ BuMA $_{10.5}-b$-DEAEMA 12 & 12.7 & 16.9 & 24.4 & 32.7 & 13.5 & 28.2 & 6.4 & 61 \\
\hline 6 & PEGMA $_{11}-b-\mathrm{BuMA}_{10.5}-b-\mathrm{DEAEMA}{ }_{14}$ & 12.0 & 15.5 & 24.4 & 15.7 & 24.4 & 21.0 & 6.7 & 53 \\
\hline
\end{tabular}

${ }^{a}$ PEGMA, BuMA and DEAMA are the abbreviations for penta(ethylene glycol) methyl ether methacrylate, $n$-butyl methacrylate, and 2-(diethylamino)ethyl methacrylate, respectively.

$\mathrm{b}$ The theoretical calculations were based on the experimental degrees of polymerisations (DPs), as resulted from GPC analysis after precipitation and ${ }^{1} \mathrm{H}$ NMR analysis before precipitation.

${ }^{c}$ In model 1, the cores of the micelles were formed only by the hydrophobic BuMA blocks, while the corona of the micelle formed by both PEGMA blocks and DEAEMA blocks. The equation used to calculate the hydrodynamic diameter is $d_{H}=\left[\mathrm{DP}_{\mathrm{BuMA}}+2^{*} \mathrm{DP} \mathrm{P}_{\text {longest hydrophilic }}\right.$ ]$^{\star} 0.254 \mathrm{~nm}$.

d In model 2, both BuMA blocks and DEAEMA blocks contributed to the formation of the cores of the micelles, while the corona of the micelle was formed by PEGMA blocks only. The equation used to calculate the hydrodynamic diameter is $d_{H}=\left[\left(D_{\text {BuMA }}+D_{\text {DEAEMA }}\right)+\right.$ $2^{*}$ DP PEGMA $]^{*} 0.254 \mathrm{~nm}$.

e The results reported are the average of the size corresponding to the maximum by intensity. In case more than one peak was detected, the results reported are the ones corresponding to the peak of micelles.

${ }^{\mathrm{f}}$ The initial $\mathrm{pH}$ of the polymer solutions varied between 7.1-7.6.

9 The CPs were tested at the initial $\mathrm{pH}$ of the polymer solutions in $\mathrm{DI}$ water.

\section{Hydrodynamic Diameters}

As DEAEMA is a monomer with tunable hydrophobicity, the self-assembly behaviour (micelle size and size distribution) of the copolymer solutions at $1 \mathrm{w} / \mathrm{w} \%$ has been 
thoroughly investigated in different aqueous media by DLS: i) DI water at initial $\mathrm{pH}(\mathrm{pH}$ between 7.1 to 7.6, depending on the strength of the amine groups), ii) DI water at alkaline $\mathrm{pH}(\mathrm{pH} 8)$ to ensure complete deprotonation of the DEAEMA units and thus hydrophobic character, iii) DI water at acidic $\mathrm{pH}(\mathrm{pH} 5)$ at which complete protonation of the DEAEMA units takes place and thus they are hydrophilic, and iv) PBS. The hydrodynamic diameters have been experimentally determined and compared to the calculated ones.

For the theoretical calculations, two models are proposed and are illustrated in Figure 4 below. The proposed self-assembly structures of Polymer 1 are shown as an example. In the first model (structure shown on the left), the hydrophobic BuMA (shown in red) forms the core of the micelle, while the corona consists of both PEGMA (represented by light blue spheres) and DEAEMA (shown in yellow); in this model, it is assumed that DEAEMA is hydrophilic, which is the case at $\mathrm{pH}$ values below its $p K_{\text {a. }}$. In the second model (structure shown on the right), the core is formed by both BuMA and DEAEMA, while PEGMA contributes to the corona of the micelle; this is the case when the $\mathrm{pH}$ is higher than the $\mathrm{p} K_{\mathrm{a}}$ value of the DEAEMA units. In both models and derivation of the corresponding equations, it is assumed that i) the hydrophobic block(s) form(s) the core of the micelle, while the hydrophilic block(s) form the corona of the micelles, ii) the hydrophobic part fully overlaps, iii) only the methacrylate backbone contributes to the micelle size (i.e. length side chains, e.g. in PEGMA, are not taken into consideration), iv) the methacrylate backbone is fully extended, v) the projected length of a methacrylate backbone equal to $0.254 \mathrm{~nm}$ is considered.
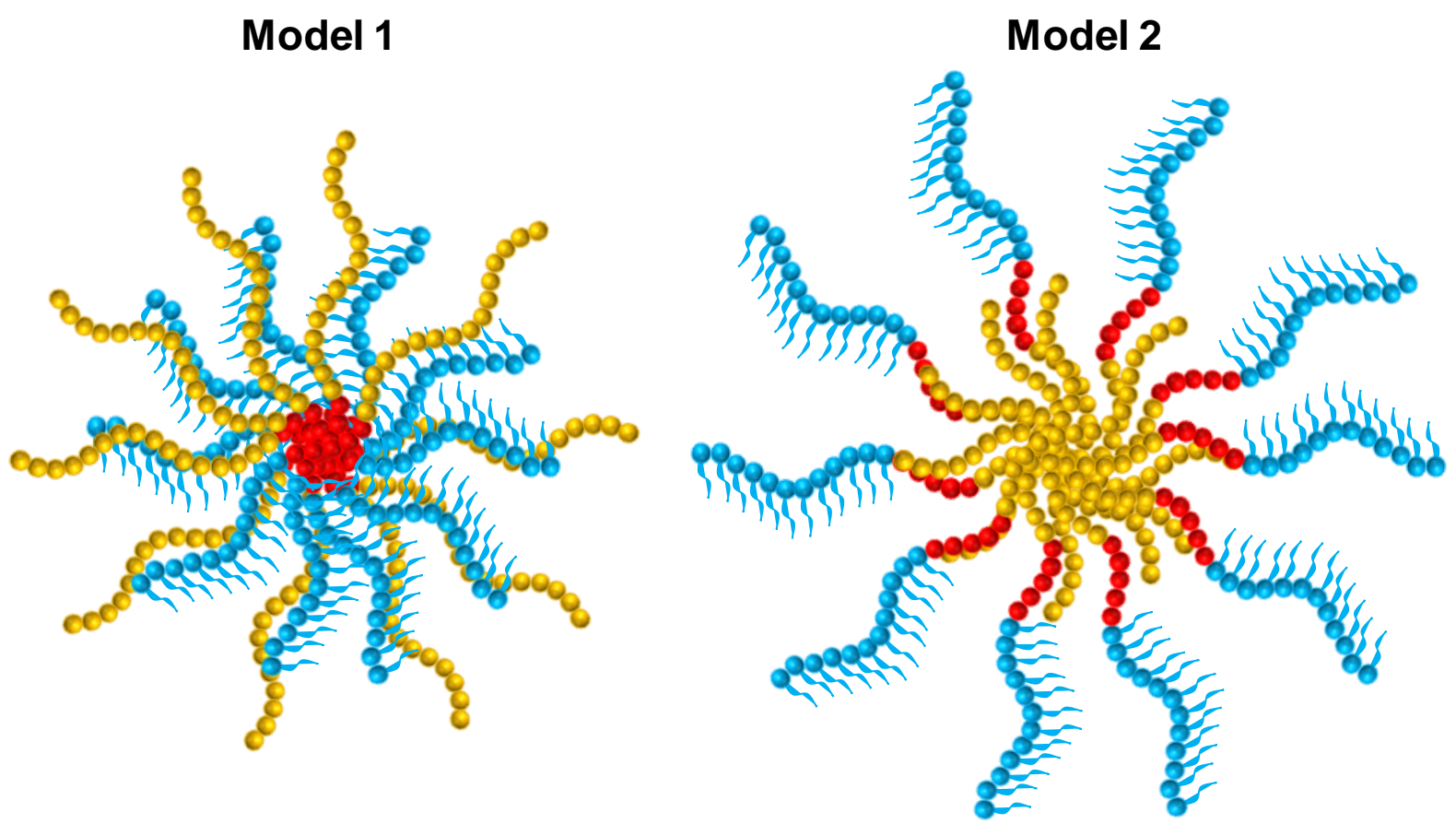

Figure 4: Schematic representation of the suggested micelle configuration adopted by Polymer 1. Model 1 (left) assumes that the core is formed only by the hydrophobic BuMA units (red spheres), while Model 2 (right) assumes that both BuMA and DEAEMA (yellow spheres) units contribute to the core of the micelle. 
As previously mentioned, Table 2 includes the experimental peak by intensity that corresponds to the micelle size (around $10 \leq d_{\mathrm{H}} \leq 50 \mathrm{~nm}$ ). Depending on the polymer composition, the $\mathrm{pH}$ of the aqueous solution and the solvent (DI water versus PBS), more than one peaks might be detected, which indicates the presence of species of various sizes. Specifically, unimers $\left(d_{\mathrm{H}} \leq 10 \mathrm{~nm}\right)$ and aggregates $\left(d_{\mathrm{H}} \geq 100 \mathrm{~nm}\right)$ might be present. The PDI values, which indicate the homogeneity of the samples, are presented in the SI (Table S2), as well as the full histograms (Figures S3-S6). It is noteworthy, that at acidic $\mathrm{pH}$, the micelle structures seem to be disrupted, as most of the polymer solutions consist of unimers and aggregates, in addition to the micelles. Remarkably, the polymer solutions in PBS, which is the solvent that the gelation is investigated in, are monodisperse, as indicated by the low PDI values (0.035-0.156), and the presence of only one peak that corresponds to the micelles.

When either of the calculated diameters are compared to the experimental hydrodynamic diameters by intensity, it is observed that the experimental values are in most of the cases higher than the theoretical ones, regardless the $\mathrm{pH}$ of the solution or the solvent (DI water versus PBS). This opposes to the expected trend,[38, 42, 67, $78,79]$ and it can be ascribed to i) the poor overlap of the hydrophobic part due to either electrostatic repulsions and/or steric hindrance, and ii) the theoretical calculations not taking into consideration any contributions of the length of the side chain. Interestingly, in most of the cases, the hydrodynamic diameters at alkaline $\mathrm{pH}$ (at which the DEAEMA units are hydrophobic) are higher than those at acidic $\mathrm{pH}$ (at which the amine groups are hydrophilic). This can be explained upon consideration of the amine groups contributing to the core formation and thus leading to formation of bigger micelles (see Figure 4).

\section{Dissociation Constants (pKas)}

As the polymer contains an amine-based repeated unit, their aqueous solutions were characterised by hydrogen ion titrations and their $\mathrm{p} K_{\mathrm{a}}$ s were calculated and listed in Table 2. As can be seen, the $\mathrm{p} K_{\mathrm{a}}$ values vary from 6.2 to 7.1 , which are composition dependent. As can be seen, all the copolymers with $10 \mathrm{w} / \mathrm{w} \%$ BuMA content show $\mathrm{p} K_{\mathrm{a}}$ between 6.8 and 7.1. This range is in high agreement with the results of our recentlypublished study, in which copolymers based only on DEAEMA and PEGMA were studied.[72] Nevertheless, an important drop on the $p K_{a}$ is observed when the content in BuMA is increased to $20 \mathrm{w} / \mathrm{w} \%$, with the values being between 6.2 and 6.7. The effect of the hydrophobicity on the $p K_{a}$ has been reported previously,[42] and it is explained by the reduced dielectric constant caused by the increased hydrophobicity.

\section{Cloud Points}

As this study focuses on the thermoresponsive properties of novel terpolymers by varying the composition, as well as the effect of the $\mathrm{pH}$ response of DEAEMA units on the thermoresponsive behaviour, the CPs were investigated at $1 \mathrm{w} / \mathrm{w} \%$ polymer concentration in three different environments: i) $\mathrm{DI}$ water at initial $\mathrm{pH}$, ii) DI water at 
alkaline $\mathrm{pH}(\mathrm{pH} 8)$, and iii) PBS; the results are presented in Figure 5 below in squares, triangles, and circles, respectively.

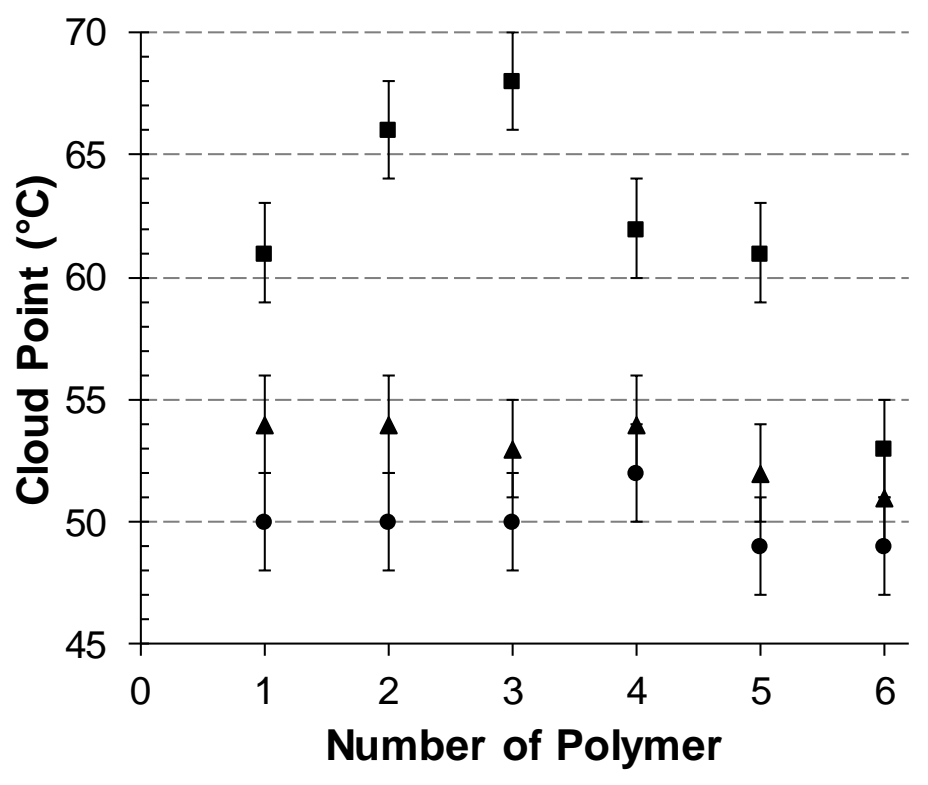

- DI water initial pH $\quad \Delta$ DI water $\mathrm{pH} 8$ - PBS

Figure 5: Effect of the $\mathrm{pH}$ (initial $\mathrm{pH}$ and $\mathrm{pH} 8$ ) and effect of the solvent (DI water versus PBS) on the CP of the $1 \mathrm{w} / \mathrm{w} \%$ copolymer solutions. The error of the technique is $\pm 2{ }^{\circ} \mathrm{C}$. Note: Polymers 1-3 have $10 \mathrm{w} / \mathrm{w} \%$ hydrophobic BuMA content, while Polymers $4-5$ have $20 \mathrm{w} / \mathrm{w} \%$ BuMA content. In both families, the DEAEMA content increases from Polymers 1-3 and 4-6, respectively.

As can be seen in Figure 5, two effects can be drawn concerning the CPs at initial pH (squares). Regarding the copolymers with only $10 \mathrm{w} / \mathrm{w} \%$ BuMA content (Polymer 1 to 3), the CP increases from $61^{\circ} \mathrm{C}$ to $68^{\circ} \mathrm{C}$ by decreasing the DEAEMA content increases (or the PEGMA content decreases). On the other hand, the CPs of the copolymers with $20 \mathrm{w} / \mathrm{w} \%$ BuMA (Polymer 4 to 6 ) drops from $62^{\circ} \mathrm{C}$ to $53^{\circ} \mathrm{C}$ as the DEAEMA content increases (or the PEGMA content decreases); this trend has been observed before in PEGMA-DEAEMA based copolymers.[72] The CPs are comparable with the ones resulted in our latest study, in which they varied from $61^{\circ} \mathrm{C}$ to $57^{\circ} \mathrm{C}$ as the content in DEAEMA increased.[72] However, it should be reminded that the initial $\mathrm{pH}$ of the solutions varied from 7.1 to 7.6, polymer dependent, which indicates different degrees of ionisation of the DEAEMA units, which could affect the CP values.

To confirm our hypothesis and eliminate any effects resulting from varying degrees of ionisation on the CPs, the $\mathrm{pH}$ was adjusted to 8 , to ensure complete deprotonation of the amine groups and to eliminate any effect of the electrostatic interactions on the $\mathrm{CP}$. The CPs at alkaline $\mathrm{pH}$ are presented in Figure 5 (in triangles). As can be seen, the $\mathrm{CPs}$ at alkaline $\mathrm{pH}$ vary between $54^{\circ} \mathrm{C}$ to $51^{\circ} \mathrm{C}$ and they are consistently lower than the CPs at initial $\mathrm{pH}$. This is expected as the complete deprotonation of the DEAEMA units ensures that they are at the hydrophobic state, which enhances the "hydrophobic" effect, thus lowering the CPs. Therefore, it is expected that decreasing the $\mathrm{pH}$ below the $\mathrm{pK}$ a will result to increase in the CP. This has been previously observed on DMAEMA-containing polymers.[41, 80, 81] The lowest CP is presented 
by Polymer $6\left(\mathrm{CP}\right.$ at $\left.51^{\circ} \mathrm{C}\right)$, which might be attributed to its smaller micelle size formed at $\mathrm{pH}$ 8, i.e. $15.7 \mathrm{~nm}$ versus $28.2-32.7 \mathrm{~nm}$. This agrees with the previous findings by our group on DMAEMA-containing polymers.[42] Interestingly, when comparing the $\mathrm{CPs}$ of the copolymers at $\mathrm{pH} 8$ with PEGMA homopolymers of comparable molar mass as the PEGMA block (unpublished data), it is observed that the CPs of the triblock copolymers are much lower than those of the PEGMA homopolymers (around $77^{\circ} \mathrm{C}$ ). Thus, it can be concluded that the incorporation of both BuMA and DEAEMA units in the polymer structure favours the thermoresponse by lowering the CPs.

The CPs in PBS are also shown in Figure 5 (in circles) and they vary between $49^{\circ} \mathrm{C}$ and $52^{\circ} \mathrm{C}$. It is observed that the increase in ionic strength reduces the $\mathrm{CP}$ values. This has been observed before on ionisable polymers and can be attributed to the ionic strength effect.[80, 82]

\section{Phase Diagrams}

The concentrated polymer solutions have also been investigated for gelation and the results are presented in means of phase diagrams in Figure 6. The effect of BuMA composition is presented from the top to the bottom, while the effect of the PEGMA/DEAEMA composition is presented from the left to the right. The polymer solutions were inspected for presenting 9 different transitions: (i) runny solution phase in white (squares, triangles and circles for transparency, slight cloudiness and cloudiness, respectively), ii) viscous solution phase in red (triangles and circles for transparency and cloudiness, respectively), iii) stable gel phase in blue (triangles and circles for transparency and cloudiness, respectively), and iv) two phases in yellow (rhombi and squares for gel syneresis and precipitation, respectively). 


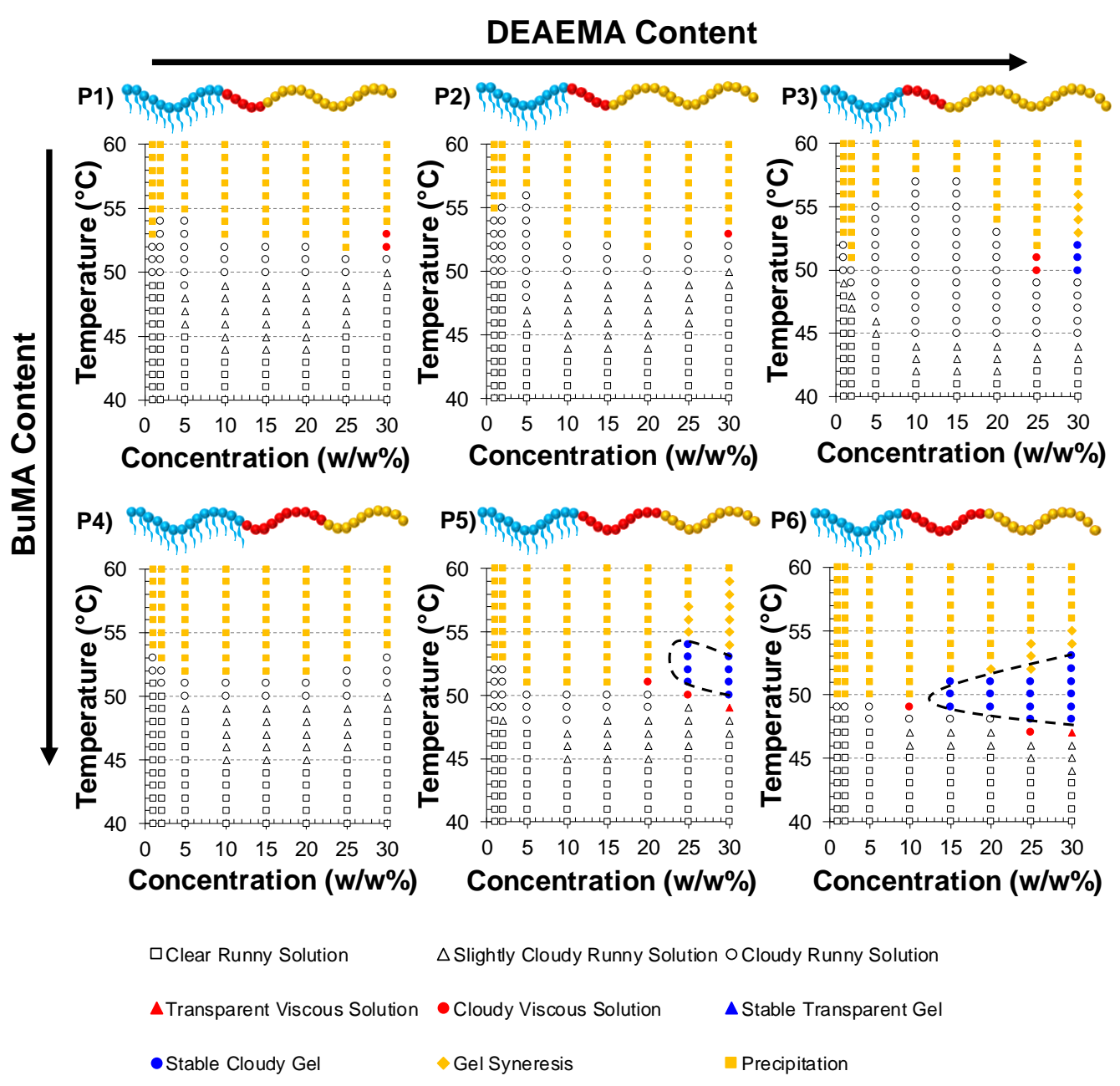

Figure 6: Detailed phase diagrams of all the soluble polymers (P1-P6) in phosphate buffered saline (PBS). The effect of the BuMA content is shown from the top to the bottom, whereas the effect of the DEAEMA content is shown from the left to the right. The runny solution phase is presented in white symbols (square, triangle and circle show clear, slightly cloudy, and cloudy solution), while the viscous solution phase is symbolised in red triangles (transparent) and circles (cloudy). The stable gel phase is coloured in blue triangles (transparent) and circles (cloudy), whereas when two-phases are present, i.e. gel syneresis and precipitation, are represented by yellow rhombus and squares, respectively. The gelation area, i.e. temperature and concentration values that a stable gel is formed, is drawn in black dashed line. The corresponding polymer structures are also schematically illustrated, with PEGMA, BuMA, and DEAEMA represented by blue, red, and yellow spheres, respectively.

In Figure 6, it can be observed that all the copolymer solutions show thermoresponse upon heating. More specifically, all the copolymer solutions, regardless the polymer composition and concentration, present a CP as the temperature increases. Upon further heating, phase separation occurs at all cases.

Interestingly, clear effects of the BuMA and DEAEMA contents on the thermoresponse are observed. It can be clearly concluded that by increasing the BuMA content from $10 \mathrm{w} / \mathrm{w} \%$ to $20 \mathrm{w} / \mathrm{w} \%$, the gelation is favoured. Concerning the family of $10 \mathrm{w} / \mathrm{w} \%$ BuMA (Polymers 1, 2 and 3), only Polymer 3, with the highest content in DEAEMA, 
forms gels at the highest concentration tested. In contrast, Polymers 1 and 2, which have the same BuMA content as Polymer 3 but lower DEAEMA content, only precipitate upon heating, with the exemption of their concentrated polymer solutions that pass through a viscous solution state prior to clear phase separation. On the other hand, concerning the copolymers with $20 \mathrm{w} / \mathrm{w} \%$ BuMA, both Polymer 5 and 6 form gels upon heating, while Polymer 4, with the lowest DEAEMA content, precipitates regardless the concentration. Also, as can be seen in Figure 8, Polymer 6 presents the widest gelation area of all the copolymers tested. Specifically, Polymer 6 gels at a concentration of at least $15 \mathrm{w} / \mathrm{w} \%$, while its most concentrated polymer solution forms a gel from $48^{\circ} \mathrm{C}$ to $53^{\circ} \mathrm{C}$. The better thermogelling properties of Polymer 6 are attributed to its high BuMA and DEAEMA content. Therefore, it can be concluded that both BuMA and DEAEMA favour the gelation, as they enhance the "hydrophobic effect" in thermoresponsive polymers, which supports the previous findings.[38, 40, 42, 67]

\section{Rheological Properties}

Polymer 6, which showed the best gelation properties visually, has been tested at 30 $\mathrm{w} / \mathrm{w} \%$ in PBS via rheology and the results are presented in Figure 7 below. Three different measurement types have been carried out: (a) temperature ramp measurements, (b) time sweep measurements and (c) flow sweep measurements.

(a)

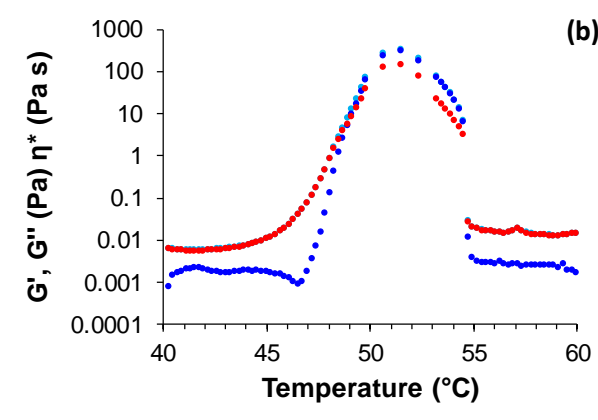

(b)

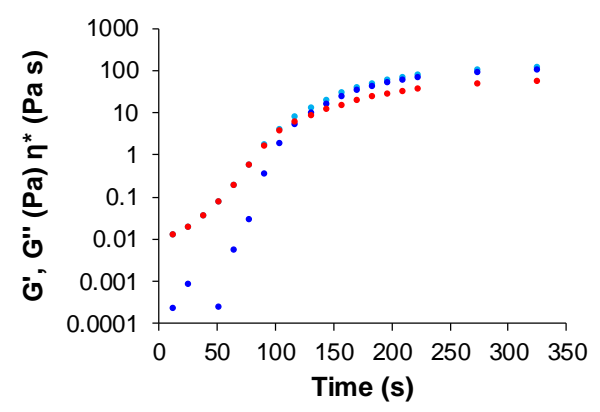

- Complex Viscosity (Pa s) - Storage Modulus (Pa) - Loss Modulus (Pa)

(c)

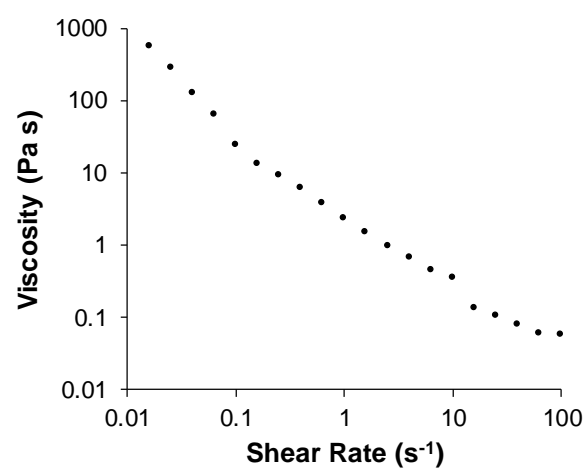

Figure 7: Rheological measurements performed at $30 \mathrm{w} / \mathrm{w} \%$ solution of Polymer 6 PEGMA $_{11}$ $b$-BuMA ${ }_{10.5}-b$-DEAEMA ${ }_{14}$ ) in phosphate buffered saline (PBS): (a) temperature ramp measurement (storage modulus, G', in blue, loss modulus, G", in red, and complex viscosity, $\eta^{*}$, in light blue), (b) time sweep measurements at $49^{\circ} \mathrm{C}$ (storage modulus, $\mathrm{G}^{\prime}$, in blue, loss modulus, G", in red, and complex viscosity, $\eta^{*}$, in light blue), and (c) flow sweep measurements (viscosity versus shear rate) at $49^{\circ} \mathrm{C}$. 
Concerning the temperature ramp measurement (Figure 7(a)), gelation is observed upon temperature increase, as the storage modulus ( $G^{\prime}$, shown in blue) exceeds the loss modulus ( $G^{\prime \prime}$, shown in red). Further increase in temperature leads to gel destabilisation, as expected from the visual tests. More specifically, a gel is formed rheologically at $49^{\circ} \mathrm{C}$, while it is disrupted at $55^{\circ} \mathrm{C}$. These temperature values are in high agreement with the results by visual tests, within the error of the techniques, as a gel was formed visually at $48^{\circ} \mathrm{C}$, gel syneresis was presented at $53^{\circ} \mathrm{C}$, and precipitation occurred at $55^{\circ} \mathrm{C}$. Therefore, it is concluded that rheology confirms the visual tests.

To expand the rheological evaluation, the same polymer solution has been also tested in terms of its gelation time and shear-thinning properties at $49^{\circ} \mathrm{C}$, and the results are presented in Figure 7(b) and 7(c), respectively. As can be seen in Figure 7(b), both moduli (storage modulus, G', in blue and loss modulus, G", in red) increase in magnitude as the time passes, and at 130s there is a crossover of the two moduli ( $G^{\prime}$ '> $\left.\mathrm{G}^{\prime \prime}\right)$, which indicates that gelation takes place. Interestingly, the gel possesses shearthinning properties, as the viscosity decreases with increased shear rate (see Figure 7(c), which is important especially in 3D printing.[27-29] 


\section{Conclusions}

This study presents the synthesis and characterisation of novel thermoresponsive polymers based on PEGMA, BuMA, and DEAEMA. Six triblock copolymers (PEGMAx$b$-BuMA $A_{y}-b$-DEAEMAz), of the same total molar mass and architecture but various compositions were systematically investigated in terms of their thermoresponsive properties; $x, y$, and $z$ are the degrees of polymerisation of PEGMA, BuMA, and DEAEMA units, respectively. All the copolymers were successfully synthesised via GTP and their solubility in aqueous media was tested. Their $\mathrm{p} K \mathrm{a}$ values were investigated and it has been found to be affected by the BuMA content. The effects of the degree of ionisation and the ionic strength on the self-assembly behaviour have been thoroughly investigated by DLS. The aqueous polymer solutions have been extensively studied for visual changes at various temperatures. The detailed phase diagrams prove that the gelation is strongly governed by the content in DEAEMA and BuMA. The gelation of the best-performing polymer has been investigated rheologically, and its gelation temperature, gelation time and shear-thinning properties have been determined.

\section{Declaration of Competing Interest}

The authors declare no competing interest.

\section{Acknowledgements}

EPSRC is acknowledged for funding APC's fellowship and DRC's PhD studies. The Department of Materials at Imperial College London is thanked for funding APC's PhD studies. 


\section{References}

[1] M.A. Ward, T.K. Georgiou, Thermoresponsive polymers for biomedical applications, Polymers 3 (2011) 1215-1242. https://www.mdpi.com/20734360/3/3/1215.

[2] A.P. Constantinou, T.K. Georgiou, Tuning the gelation of thermoresponsive gels, $\begin{array}{lllll}\text { Eur. } & \text { Polym. } & \text { J. } & 78 & \text { (2016) }\end{array}$ https://www.sciencedirect.com/science/article/pii/S0014305716300702.

[4] J. Seuring, S. Agarwal, Polymers with upper critical solution temperature in aqueous solution, Macromol. Rapid Commun. 33 (2012) 1898-1920. https://doi.org/10.1002/marc.201200433.

[5] A.P. Constantinou, T.K. Georgiou, Thermoresponsive multiblock copolymers: Chemistry, properties and applications, in: V.V. Khutoryanskiy, T.K. Georgiou (Eds.) Temperature-Responsive Polymers: Chemistry, Properties, and Applications, John Wiley \& Son Ltd, United Kingdom, 2018, pp. 35-65.

[6] J. Niskanen, H. Tenhu, How to manipulate the upper critical solution temperature (UCST)? Polym. Chem. 8 (2017) 220-232. http://dx.doi.org/10.1039/C6PY01612J.

[7] A. Salamon, S. van Vlierberghe, I. van Nieuwenhove, F. Baudisch, G. Graulus, V. Benecke, K. Alberti, H. Neumann, J. Rychly, J.C. Martins, P. Dubruel, K. Peters, Gelatin-based hydrogels promote chondrogenic differentiation of human adipose tissue-derived mesenchymal stem cells in vitro, Materials 7 (2014) 1342-1359. https://www.ncbi.nlm.nih.gov/pubmed/28788517.

[8] E.S. Place, J.H. George, C.K. Williams, M.M. Stevens, Synthetic polymer scaffolds for tissue engineering, Chem. Soc. Rev. 38 (2009) 1139-1151. http://dx.doi.org/10.1039/B811392K.

[9] A. Gutowska, B. Jeong, M. Jasionowski, Injectable gels for tissue engineering, Anat. Rec. 263 (2001) 342-349. https://doi.org/10.1002/ar.1115.

[11] S. Bobbala, V. Tamboli, A. McDowell, A.K. Mitra, S. Hook, Novel injectable pentablock copolymer based thermoresponsive hydrogels for sustained release $\begin{array}{lllll}\text { vaccines, } & \text { AAPS } & \text { Journal } & 18 & \text { (2016) }\end{array}$ https://link.springer.com/article/10.1208\%2Fs12248-015-9843-4.

[12] B. Xie, L. Jin, Z. Luo, J. Yu, S. Shi, Z. Zhang, M. Shen, H. Chen, X. Li, Z. Song, An injectable thermosensitive polymeric hydrogel for sustained release of Avastin1 to treat posterior segment disease, Int. J. Pharm. 490 (2015) 375-383. https://www.sciencedirect.com/science/article/pii/S0378517315005001?via\%3Dihub. [13] C. Gong, S. Shi, L. Wu, M. Gou, Q. Yin, Q. Guo, P. Dong, F. Zhang, F. Luo, X. Zhao, Y. Wei, Z. Qian, Biodegradable in situ gel-forming controlled drug delivery system based on thermosensitive PCL-PEG-PCL hydrogel. part 2: Sol-gel-sol transition and drug delivery behavior, Acta Biomaterialia 5 (2009) 3358-3370. https://www.sciencedirect.com/science/article/pii/S1742706109002396.

[14] Q. Wu, C. Gong, S. Shi, Y. Wang, M. Huang, L. Yang, X. Zhao, Y. Wei, Z. Qian, Mannan loaded biodegradable and injectable thermosensitive PCL-PEG-PCL hydrogel for vaccine delivery, Soft Materials 10 (2012) 472-486. https://www.tandfonline.com/doi/full/10.1080/1539445X.2010.537422.

[16] R. Suntornnond, J. An, C.K. Chua, Bioprinting of thermoresponsive hydrogels for next generation tissue engineering: A review, Macromol. Mater. Eng. 302 (2017) 1600266. https://doi-org.iclibezp1.cc.ic.ac.uk/10.1002/mame.201600266.

[17] L. Klouda. Thermoresponsive hydrogels in biomedical applications: A seven-year

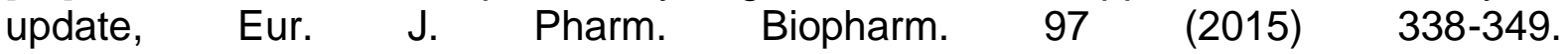
https://doi.org/10.1016/i.ejpb.2015.05.017. 
[18] E. Feilden, C. Ferraro, Q. Zhang, E. García-Tuñón, E. D’Elia, F. Giuliani, L. Vandeperre, E. Saiz, 3D printing bioinspired ceramic composites, Scientific Reports 7 (2017) 13759. https://doi.org/10.1038/s41598-017-14236-9.

[19] V.G. Rocha, E. García-Tuñón, C. Botas, F. Markoulidis, E. Feilden, E. D'Elia, N. $\mathrm{Ni}$, M. Shaffer, E. Saiz, Multimaterial 3D printing of graphene-based electrodes for electrochemical energy storage using thermoresponsive inks, ACS Appl. Mater. Interfaces 9 (2017) 37136-37145. https://doi.org/10.1021/acsami.7b10285.

[21] M. Zhang, A. Vora, W. Han, R.J. Wojtecki, H. Maune, A.B.A. Le, L.E. Thompson, G.M. McClelland, F. Ribet, A.C. Engler, A. Nelson, Dual-responsive hydrogels for direct-write 3D printing, Macromolecules $48 \quad$ (2015) 6482-6488. https://pubs.acs.org/doi/abs/10.1021/acs.macromol.5b01550.

[22] M. Müller, J. AU - Becher, M. AU - Schnabelrauch, M. AU - Zenobi-Wong, Printing thermoresponsive reverse molds for the creation of patterned two-component hydrogels for 3D cell culture, JoVE (2013) e50632. https://www.jove.com/video/50632. [23] D.B. Kolesky, R.L. Truby, A.S. Gladman, T.A. Busbee, K.A. Homan, J.A. Lewis, $3 \mathrm{D}$ bioprinting of vascularized, heterogeneous cell-laden tissue constructs, Adv Mater 26 (2014) 3124-3130. https://doi.org/10.1002/adma.201305506.

[25] Y. Tsukamoto, T. Akagi, F. Shima, M. Akashi, Fabrication of orientation-controlled 3D tissues using a layer-by-layer technique and 3D printed a thermoresponsive gel frame, Tissue Engineering Part C: Methods 23 (2017) 357-366. https://doiorg.iclibezp1.cc.ic.ac.uk/10.1089/ten.tec.2017.0134.

[26] F.-. Hsieh, H.-. Lin, S.-. Hsu, 3D bioprinting of neural stem cell-laden thermoresponsive biodegradable polyurethane hydrogel and potential in central $\begin{array}{llllll}\text { nervous system } & \text { repair, } & \text { Biomaterials } & 71 & \text { (2015) }\end{array}$ http://www.scopus.com/inward/record.url?eid=2-s2.0-

84941560619\&partnerID=40\&md5=a1987f1800f49faffbcd76ccbe770fdc.

[27] A. Basu, A. Saha, C. Goodman, R.T. Shafranek, A. Nelson, Catalytically initiated gel-in-gel printing of composite hydrogels, ACS Appl. Mater. Interfaces 9 (2017) 40898-40904. https://doi.org/10.1021/acsami.7b14177.

[28] T. Lorson, S. Jaksch, M.M. Lübtow, T. Jüngst, J. Groll, T. Lühmann, R. Luxenhofer, A thermogelling supramolecular hydrogel with sponge-like morphology as a cytocompatible bioink, Biomacromolecules 18 (2017) 2161-2171. https://doi.org/10.1021/acs.biomac.7b00481.

[29] A. Skardal, A. Atala, Biomaterials for integration with 3-D bioprinting, Ann. Biomed. Eng. 43 (2015) 730-746. https://www.ncbi.nlm.nih.gov/pubmed/25476164.

[30] H.G. Schild, D.A. Tirrell, Microcalorimetric detection of lower critical solution temperatures in aqueous polymer solutions, J. Phys. Chem. 94 (1990) 4352-4356. https://doi.org/10.1021/j100373a088.

[32] J. Lutz, Ö Akdemir, A. Hoth, Point by point comparison of two thermosensitive polymers exhibiting a similar LCST: Is the age of poly(NIPAM) over? J. Am. Chem. Soc. 128 (2006) 13046-13047. https://doi.org/10.1021/ja065324n.

[33] K. Skrabania, J. Kristen, A. Laschewsky, Ö Akdemir, A. Hoth, J. Lutz, Design, synthesis, and aqueous aggregation behavior of nonionic single and multiple thermoresponsive polymers, Langmuir $23 \quad$ (2007) 84-93. https://doi.org/10.1021/la061509w.

[34] S. Saeki, N. Kuwahara, M. Nakata, M. Kaneko, Phase separation of poly(ethylene glycol)-water-salt systems, Polymer $18 \quad$ (1977) 1027-1031. https://www.sciencedirect.com/science/article/pii/0032386177900076. 
[35] S. Saeki, N. Kuwahara, M. Nakata, M. Kaneko, Upper and lower critical solution temperatures in poly (ethylene glycol) solutions, Polymer 17 (1976) 685-689. https://www.sciencedirect.com/science/article/pii/0032386176902081.

[36] V. Bütün, S.P. Armes, N.C. Billingham, Synthesis and aqueous solution properties of near-monodisperse tertiary amine methacrylate homopolymers and diblock $\begin{array}{lllll}\text { copolymers, } & \text { Polymer } & 42 & \text { (2001) 5993-6008. }\end{array}$ https://www.sciencedirect.com/science/article/pii/S0032386101000660.

[37] M.A. Ward, T.K. Georgiou, Multicompartment thermoresponsive gels: Does the length of the hydrophobic side group matter? Polym. Chem. 4 (2013) 1893-1902. http://dx.doi.org/10.1039/C2PY21032K.

[38] M.A. Ward, T.K. Georgiou, Thermoresponsive triblock copolymers based on methacrylate monomers: Effect of molecular weight and composition, Soft Matter 8 (2012) 2737-2745. http://dx.doi.org/10.1039/C2SM06743A.

[39] M.A. Ward, T.K. Georgiou, Thermoresponsive terpolymers based on methacrylate monomers: Effect of architecture and composition, J. Polym. Sci. A Polym. Chem. 48 (2010) 775-783. https://doi.org/10.1002/pola.23825.

[40] M.A. Ward, T.K. Georgiou, Thermoresponsive gels based on ABA triblock copolymers: Does the asymmetry matter? J. Polym. Sci. Part A: Polym. Chem. 51 (2013) 2850-2859. https://doi.org/10.1002/pola.26674.

[41] A.P. Constantinou, H. Zhao, C.M. McGilvery, A.E. Porter, T.K. Georgiou, A comprehensive systematic study on thermoresponsive gels: Beyond the common architectures of linear terpolymers, Polymers $9 \quad$ (2017) 31. https://www.mdpi.com/2073-4360/9/1/31.

[42] A.P. Constantinou, N. Sam-Soon, D.R. Carroll, T.K. Georgiou, Thermoresponsive tetrablock terpolymers: Effect of architecture and composition on gelling behavior, Macromolecules $51 \quad$ (2018) 7019-7031. https://doi.org/10.1021/acs.macromol.8b01251.

[43] W. Steinhauer, R. Hoogenboom, H. Keul, M. Moeller, Block and gradient copolymers of 2-hydroxyethyl acrylate and 2-methoxyethyl acrylate via RAFT: Polymerization kinetics, thermoresponsive properties, and micellization, Macromolecules $46 \quad$ (2013) 1447-1460. https://pubs.acs.org/doi/abs/10.1021/ma302606x.

[44] J. Adelsberger, A.M. Bivigou-Koumba, A. Miasnikova, P. Busch, A. Laschewsky, P. Müller-Buschbaum, C.M. Papadakis, Polystyrene-block-poly (methoxy diethylene glycol acrylate)-block-polystyrene triblock copolymers in aqueous solution-a SANS study of the temperature-induced switching behavior, Colloid Polym. Sci. 293 (2015) 1515-1523. https://link.springer.com/article/10.1007/s00396-015-3535-6.

[45] I. Negru, M. Teodorescu, P.O. Stanescu, C. Draghici, A. Lungu, A. Sârbu, Thermogelation properties of $A B A$ triblock copolymers of poly (ethylene glycol) (B) and copolyacrylates of oligo(ethylene glycol)s (A) in aqueous solution, Soft Materials 11 (2013) https://www.tandfonline.com/doi/full/10.1080/1539445X.2011.597816.

[46] W. Zhu, A. Nese, K. Matyjaszewski, Thermoresponsive star triblock copolymers by combination of ROP and ATRP: From micelles to hydrogels, J.Polym.Sci.Part A 49 (2011) 1942-1952. https://onlinelibrary.wiley.com/doi/full/10.1002/pola.24611.

[48] J. Lutz, A. Hoth, K. Schade, Design of oligo(ethylene glycol)-based thermoresponsive polymers: An optimization study, Designed Monomers and Polymers 12 (2009) 343-353. https://doi.org/10.1163/156855509X448316. 
[50] R. Hoogenboom. Poly(2-oxazoline)s: A polymer class with numerous potential applications, Angewandte Chemie International Edition 48 (2009) 7978-7994. https://doi.org/10.1002/anie.200901607.

[51] M. Hruby, S.K. Filippov, J. Panek, M. Novakova, H. Mackova, J. Kucka, D. Vetvicka, K. Ulbrich, Polyoxazoline thermoresponsive micelles as radionuclide delivery systems, Macromolecular Bioscience 10 (2010) 916-924. https://www.ncbi.nlm.nih.gov/pubmed/20491128.

[52] R. Hoogenboom, H. Schlaad, Thermoresponsive poly(2-oxazoline)s, polypeptoids, and polypeptides, Polym. Chem. 8 (2017) 24-40. http://dx.doi.org/10.1039/C6PY01320A.

[54] O. Sedlacek, B.D. Monnery, S.K. Filippov, R. Hoogenboom, M. Hruby, Poly(2oxazoline)s - are they more advantageous for biomedical applications than other polymers? Macromol. Rapid Commun. 33 (2012) 1648-1662. https://doi.org/10.1002/marc.201200453.

[56] M. Almeida, M. Magalhães, F. Veiga, A. Figueiras, Poloxamers, poloxamines and polymeric micelles: Definition, structure and therapeutic applications in cancer, Journal of Polymer Research 25 (2017) 31. https://doi.org/10.1007/s10965-017-1426x.

[58] S. Baldassari, A. Solari, G. Zuccari, G. Drava, S. Pastorino, C. Fucile, V. Marini, A. Daga, A. Pattarozzi, A. Ratto, A. Ferrari, F. Mattioli, F. Barbieri, G. Caviglioli, T. Florio, Development of an injectable slow-release metformin formulation and evaluation of its potential antitumor effects, Scientific Reports 8 (2018) 3929. https://doi.org/10.1038/s41598-018-22054-w.

[59] L. Erfani Jabarian, M.R. Rouini, F. Atyabi, A. Foroumadi, S.M. Nassiri, R. Dinarvand, In vitro and in vivo evaluation of an in situ gel forming system for the delivery of PEGylated octreotide, Eur. J. Pharm. Sci. 48 (2013) 87-96. https://www.ncbi.nlm.nih.gov/pubmed/23131800.

[60] S. Bobbala, B. Gibson, A.B. Gamble, A. McDowell, S. Hook, Poloxamer 407chitosan grafted thermoresponsive hydrogels achieve synchronous and sustained release of antigen and adjuvant from single-shot vaccines, Immunol. Cell Biol. 96 (2018) 656-665. https://doi-org.iclibezp1.cc.ic.ac.uk/10.1111/imcb.12031.

[61] K. Edsman, J. Carlfors, R. Petersson, Rheological evaluation of poloxamer as an in situ gel for ophthalmic use, Eur. J. Pharm. Sci 6 (1998) 105-112. https://www.sciencedirect.com/science/article/pii/S0928098797000754.

[62] G. Dumortier, J.L. Grossiord, F. Agnely, J.C. Chaumeil, A review of poloxamer 407 pharmaceutical and pharmacological characteristics, Pharm. Res. 23 (2006) 2709-2728. https://link.springer.com/article/10.1007/s11095-006-9104-4.

[63] M. Müller, J. Becher, M. Schnabelrauch, M. Zenobi-Wong, Nanostructured pluronic hydrogels as bioinks for 3D bioprinting, Biofabrication 7 (2015) 035006. http://stacks.iop.org/1758-5090/7/i=3/a=035006.

[64] D.R. Carroll, A.P. Constantinou, N. Stingelin, T.K. Georgiou, Scalable syntheses of well-defined pentadecablock bipolymer and quintopolymer, Polym. Chem. 9 (2018) 3450-3454. http://dx.doi.org/10.1039/C8PY00565F.

[65] O.W. Webster. The discovery and commercialization of group transfer polymerization, J. Polym. Sci. A Polym. Chem. 38 (2000) 2855-2860. https://doi.org/10.1002/1099-0518(20000815)38:163.0.CO;2-S.

[66] O.W. Webster. Living polymerization methods, Science 251 (1991) 887-893. http://www.jstor.org/stable/2874896. 
[67] A.P. Constantinou, T.K. Georgiou, Thermoresponsive gels based on ABC triblock copolymers: Effect of the length of the PEG side group, Polym. Chem. 7 (2016) 20452056. http://dx.doi.org/10.1039/C5PY02072G.

[68] A.P. Constantinou, M. Elladiou, C.S. Patrickios, Regular and inverse polyampholyte hydrogels: A detailed comparison, Macromolecules 49 (2016) 38693880. https://doi.org/10.1021/acs.macromol.6b00538.

[69] M. Přádný, S. Ševčík, Precursors of hydrophilic polymers, 3. the potentiometric behaviour of isotactic and atactic poly(2-dimethylaminoethyl methacrylate) in water/ethanol solutions, Makromol. Chem. 186 (1985) 111-121. https://doi.org/10.1002/macp.1985.021860111.

[70] N.G. Hoogeveen, M.A.C. Stuart, G.J. Fleer, W. Frank, M. Arnold, Novel watersoluble block copolymers of dimethylaminoethyl methacrylate and dihydroxypropyl methacrylate, Macromol. Chem. Phys. 197 (1996) 2553-2564. https://doi.org/10.1002/macp.1996.021970818.

[71] J. Lutz. Polymerization of oligo(ethylene glycol) (meth)acrylates: Toward new generations of smart biocompatible materials, J. Polym. Sci. A Polym. Chem. 46 (2008) 3459-3470. https://doi.org/10.1002/pola.22706.

[72] A.P. Constantinou, U. Marie-Sainte, L. Peng, D.R. Carroll, C.M. McGilvery, I.E. Dunlop, T.K. Georgiou, Effect of block copolymer architecture and composition on gold $\begin{array}{llll}\text { nanoparticle fabrication, Polym.Chem. } 10 & \text { (2019) 4637-4642. }\end{array}$ http://dx.doi.org/10.1039/C9PY00931K.

[73] Q. Chen, W. Lin, H. Wang, J. Wang, L. Zhang, PDEAEMA-based pH-sensitive amphiphilic pentablock copolymers for controlled anticancer drug delivery, RSC Adv. 6 (2016) 68018-68027. http://dx.doi.org/10.1039/C6RA10757E.

[74] L. Liu, C. Wu, J. Zhang, M. Zhang, Y. Liu, X. Wang, G. Fu, Controlled polymerization of 2-(diethylamino)ethyl methacrylate and its block copolymer with $\mathrm{N}$ isopropylacrylamide by RAFT polymerization, J. Polym. Sci. A Polym. Chem. 46 (2008) 3294-3305. https://doi.org/10.1002/pola.22669.

[75] H. Feil, Y.H. Bae, J. Feijen, S.W. Kim, Mutual influence of $\mathrm{pH}$ and temperature on the swelling of ionizable and thermosensitive hydrogels, Macromolecules 25 (1992) 5528-5530. https://doi.org/10.1021/ma00046a063.

[77] I.B. Dicker, G.M. Cohen, W.B. Farnham, W.R. Hertler, E.D. Laganis, D.Y. Sogah, Oxyanions catalyze group-transfer polymerization to give living polymers, Macromolecules 23 (1990) 4034-4041. https://pubs.acs.org/doi/pdf/10.1021/ma00220a002.

[78] N.H. Raduan, T.S. Horozov, T.K. Georgiou, "Comb-like" non-ionic polymeric macrosurfactants, Soft Matter 6 (2010) 2321-2329. http://dx.doi.org/10.1039/B926822G.

[79] N. Ghasdian, D.M.A. Buzza, P.D.I. Fletcher, T.K. Georgiou, ABC triblock copolymer micelles: Spherical versus worm-like micelles depending on the preparation method, Macromol. Rapid Commun. 36 (2015) 528-532. https://onlinelibrary.wiley.com/doi/epdf/10.1002/marc.201400621.

[80] J. de Souza Carlos Perbone, A.F. Naves, F. Florenzano, Specific thermoresponsiveness of PMMA-block-PDMAEMA to selected ions and other factors in aqueous solution, Colloid Polym.Sci. 290 (2012) 1285-1291. https://doi.org/10.1007/s00396-012-2651-9.

[81] D. Fournier, R. Hoogenboom, H.M.L. Thijs, R.M. Paulus, U.S. Schubert, Tunable $\mathrm{pH}-$ and temperature-sensitive copolymer libraries by reversible additionfragmentation chain transfer copolymerizations of methacrylates, Macromolecules 40 (2007) 915-920. https://pubs.acs.org/doi/10.1021/ma062199r. 
[82] E. Florin, R. Kjellander, J.C. Eriksson, Salt effects on the cloud point of the poly(ethylene oxide)+ water system, J. Chem. Soc., Faraday Trans.1 80 (1984) 28892910. http://dx.doi.org/10.1039/F19848002889. 